Short Communication

\title{
Pansusceptible Escherichia coli isolates obtained from faeces of free-ranging Baird's tapirs (Tapirus bairdii) suggests a low selective pressure for resistance determinants in the northwestern region of the
}

\section{Talamanca Mountain Range, Costa Rica}

\author{
Jorge Rojas-Jiménez ${ }^{\mathrm{a}, \mathrm{b}, \mathrm{c}}$, Esteban Brenes-Mora ${ }^{\mathrm{a}, \mathrm{c}}$, Paloma Alcázar-García ${ }^{\mathrm{c}, \mathrm{d}}$, \\ Randall Arguedas-Porras ${ }^{\mathrm{c}, \mathrm{e}}$, Elías Barquero-Calvo ${ }^{\mathrm{f}, *}$ \\ a Nai Conservation, San José, Costa Rica \\ ${ }^{\mathrm{b}}$ IUCN/SSC Tapir Specialist Group (TSG), Gland, Switzerland \\ ${ }^{\mathrm{c}}$ Awá Science \& Conservation, Costa Rica \\ ' Centro de Ornitología y Biodiversidad (CORBIDI), Lima, Perú \\ e Zoológico Nacional Simón Bolívar, San José, Costa Rica \\ ${ }^{\mathbf{f}}$ Programa de Investigación en Enfermedades Tropicales, Escuela de Medicina Veterinaria, Universidad Nacional de Costa Rica, Heredia, Costa Rica
}

\section{A R T I C L E I N F O}

\section{Article history:}

Received 2 June 2018

Received in revised form 12 September 2018

Accepted 20 September 2018

Available online 27 September 2018

\section{Keywords:}

Escherichia coli

Antimicrobial resistance

Selective pressure

Protected area

Anthropogenic activity

Tapirus bairdii

\begin{abstract}
A B S T R A C T
Objectives: The main objective of this study was to analyse the antimicrobial susceptibility profile of Escherichia coli isolates obtained from faecal samples of free-ranging Baird's tapirs (Tapirus bairdii) in the northwestern region of the Talamanca Mountain Range, Costa Rica.

Methods: Faecal samples were collected by opportunistic search of the study area from FebruarySeptember 2017 during seven field expeditions. Escherichia coli isolates were recovered using selective and differential MacConkey agar medium and were subjected to biochemical identification and antimicrobial susceptibility testing using a VITEK ${ }^{\mathbb{R}} 2$ Compact automated system and the AST-N279 card. Results: A total of 60 E. coli isolates were obtained from 63 faecal samples. Following evaluation of nine different antimicrobial classes, $98 \%$ (59/60) of the isolates were characterised as pansusceptible; only 1 isolate presented resistance to nalidixic acid.

Conclusion: We propose that the commensal intestinal microbiota of free-ranging Baird's tapirs in this area remains isolated from antibiotic selective pressure, probably because seven different protected areas converge, thus giving a possible low anthropogenic activity to the region.
\end{abstract}

(c) 2018 International Society for Chemotherapy of Infection and Cancer. Published by Elsevier Ltd. All rights reserved.

\section{Introduction}

The Central American tapir (Baird's tapir; Tapirus bairdii) is the largest terrestrial mammal of Mesoamerica. It is distributed from southern Mexico to northwestern Colombia, with less than 4500 living individuals in its entire distribution [1,2]. Due to threats such as habitat fragmentation, hunting and, recently, road kills, tapirs are classified as an endangered species according to the International Union for Conservation of Nature (IUCN) [1,3]. They occur from sea level to 3600 m.a.s.l., inhabiting a great diversity of ecosystems throughout their range, mostly within protected areas [2].

\footnotetext{
* Corresponding author.

E-mail address: elias.barquero.calvo@una.cr (E. Barquero-Calvo).
}

Tapirs are strict herbivores, thus they play an important ecological role as an ecosystem engineer, mainly through efficient long-distance seed dispersal and selective browsing [4]. In addition, habitat occupancy and population density studies in the Talamanca Mountain Range have demonstrated that tapirs frequently cross the Pan-American Highway and move near human settlements [3,5]. Consequently, tapirs are a suitable species to test for potential exposure to antimicrobial resistance determinants disseminated by anthropogenic activity in the region.

When a wild animal acquires antimicrobial-resistant bacteria, it has the potential to function as a vector and reservoir as well as a bioindicator or sentinel species for resistant bacteria, with the potential risk of transmission and dissemination of resistance determinants throughout the environment [6,7]. Escherichia coli colonises the large intestine of mammals and constitutes a reservoir for antimicrobial resistance genes, which may play an 
important role in the dissemination of resistant bacteria [8]. Several authors [9-11] have proposed a correlation between the occurrence of resistant bacteria isolated from wild animals and their proximity to anthropogenic activity. In addition, CristóbalAzkarate et al. have already reported the presence of antimicrobial resistance genes from faecal bacteria obtained from free-ranging tapirs in Mexico [12].

Owing to the scarce research performed on antimicrobial resistance in wildlife animals in Central America and to the particular behaviour of tapirs near human settlements, the main aim of this study was to analyse the antimicrobial susceptibility profile of $E$. coli isolates obtained from faecal samples of Baird's tapirs in the northwestern region of the Talamanca Mountain Range, Coast Rica. This is the first report on antimicrobial resistance performed in free-ranging tapirs in Central America.

\section{Materials and methods}

This study was performed in the northwestern region of the Talamanca Mountain Range, a region located between San José and Cartago Provinces, in which seven different protected areas converge. These include Los Quetzales National Park (LQNP), Los Santos Forestry Reserve (LSFR), Cerro las Vueltas Biological Reserve (CVBR), Rio Macho Forestry Reserve (RMFR) and Tapanti Macizo de la Muerte National Park (TMMNP). In addition, there are two private protected areas, namely El Páramo Wildlife Refuge (PWR) and Private Reserve Iyok Ami (PRIA). The study area consisted of
$291 \mathrm{~km}^{2}$, centred on the Pan-American Highway (RN2), with the limits established 4-5 km from each side of RN2 (Fig. 1).

This area was chosen because previous reports in the Talamanca Mountain Range indicated a high density of tapirs in this area [3,5]. Recognition field trips as well as previous camera trap studies monitoring tapir trails and latrines were performed before collection. Scats from free-ranging Baird's tapirs were identified and the freshness was estimated. As a close relative to horses, tapirs are known to be anatomically analogous to them, consequently their scat morphology is very much similar to that of horses, making them easy to identify. In addition, no other terrestrial mammal with scats larger than tapirs' inhabits this area. Hence, faeces were collected by opportunistic search from February-September 2017 during seven field expeditions. Samples contaminated with soil and/or fungi, immersed in water or considered old (based on organoleptic characteristics) were excluded. Each sample (5-10 g) was collected from the centre of the scat using new nitrile gloves for each sample and a cotton swab, avoiding the surface to avoid environmental contaminants. Most faecal samples were collected in tapirs' trails or latrines. Samples were stored at $4{ }^{\circ} \mathrm{C}$ and were transported to the Bacteriology Laboratory of the School of Veterinary Medicine of the Universidad Nacional de Costa Rica (Heredia, Costa Rica) for analysis.

Samples were directly cultured on standard MacConkey agar (Oxoid Ltd., Basingstoke, UK) or MacConkey agar supplemented with $2 \mu \mathrm{g} / \mathrm{mL}$ cefotaxime (Sigma, St Louis, MO) to screen for resistance to third-generation cephalosporins and were incubated

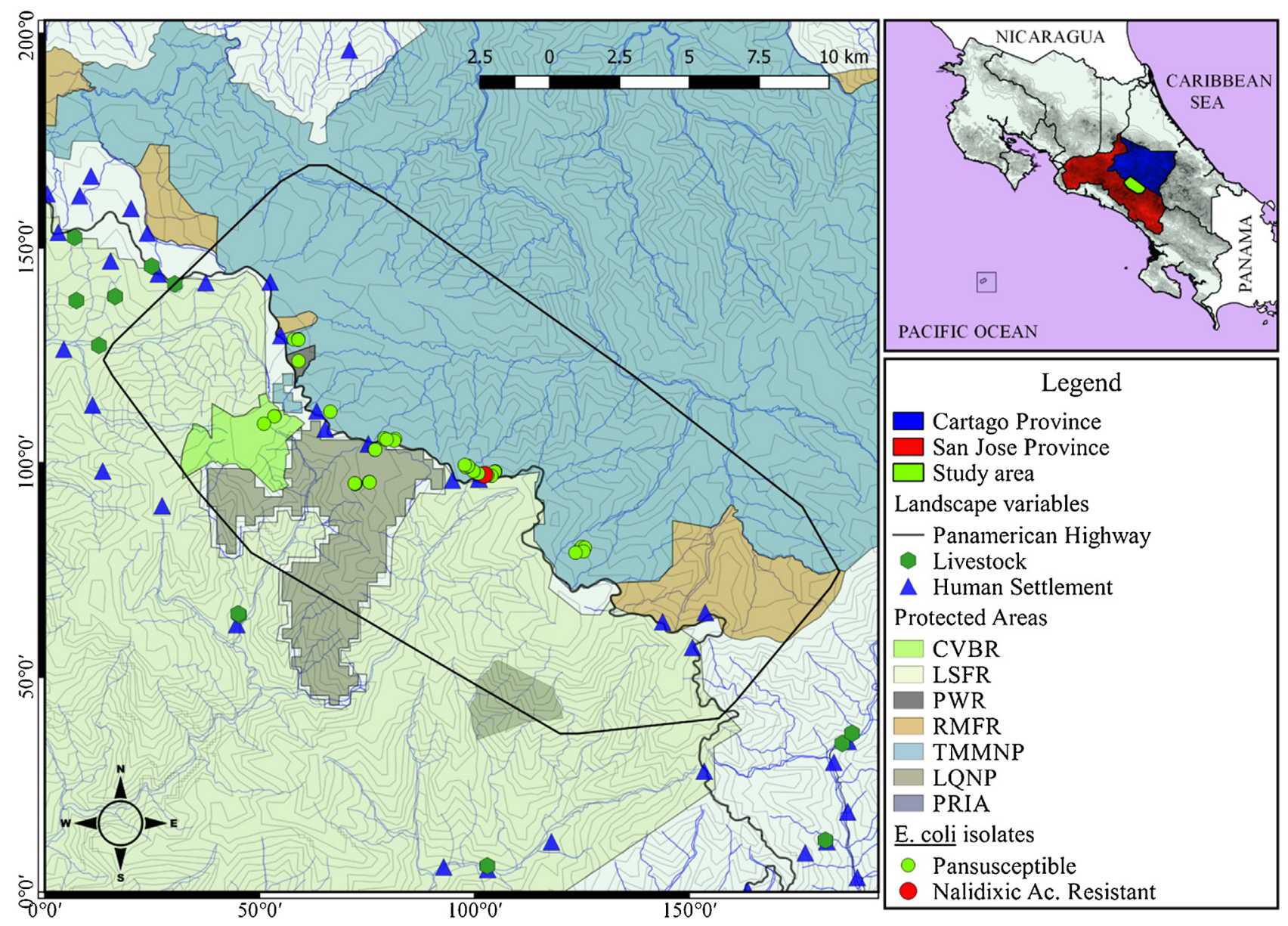

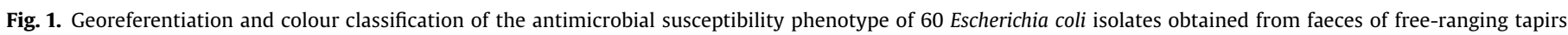

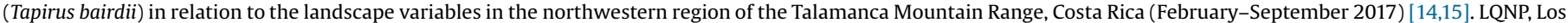

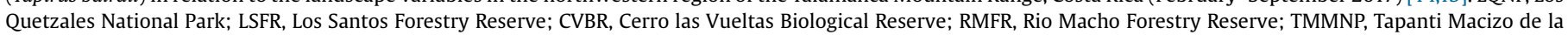
Muerte National Park; PWR, El Páramo Wildlife Refuge; PRIA, Private Reserve Iyok Ami. 
for $24 \mathrm{~h}$ at $37^{\circ} \mathrm{C}$. Typical lactose-positive E. coli colonies were screened by indole test (positive) and were further identified using a VITEK ${ }^{\circledR} 2$ Compact automated system (bioMérieux, Durham, NC) using the GN card. One colony per plate was isolated on tryptic soy agar (Oxoid Ltd.) to perform antimicrobial susceptibility testing. Escherichia coli ATCC 25922 (cefotaxime-susceptible) and Klebsiella pneumoniae ATCC 700603 (cefotaxime-resistant) were used as quality control strains.

Antimicrobial susceptibility testing was performed using a VITEK ${ }^{\mathbb{2}} 2$ Compact automated system and the AST-N279 card (bioMérieux) and the results were interpreted according to Clinical and Laboratory Standards Institute (CLSI) guidelines [13]. The ASTN279 card includes the following antibiotics: amikacin; gentamicin; cefotaxime; ceftazidime; cefepime; cefalotin; ampicillin; piperacillin/tazobactam; ampicillin/sulbactam; imipenem; meropenem; ciprofloxacin; nalidixic acid; trimethoprim/sulfonamide; colistin; and nitrofurantoin.

The geographical location of each sample was displayed in maps using QGIS Geographic Information System software [14]. The map was constructed using several layers from Costa Rica's conservation areas, protected areas, landscapes, rivers, human settlements, road network and livestock farms using the National Registry of the National Geographic Institute [15]. Landscape variables such as forest cover, land use, and distances (in $\mathrm{km}$ ) to human settlements, livestock farms, RN2 and water bodies were included in the analysis. The variables where each sample was collected were recorded and analysed descriptively, measuring the distance between the collection site and each variable.

Each isolate was graphically displayed on the map and the presence or absence of antimicrobial resistance was determined. A descriptive analysis of the landscape variables was performed for each isolate.

\section{Results and discussion}

In total, 63 individual faecal samples from free-ranging Baird's tapirs were collected, including $38(60 \%)$ collected in TMMNP, 16 (25\%) in LQNP, 6 (10\%) in PRIA and 3 (5\%) in CVBR. All samples were collected in protected areas. Nineteen different latrines were sampled, and $84 \%$ of samples (53/63) were collected in latrines. In addition, $46 \%$ of samples (29/63) were collected in tapir trails, $21 \%$ $(13 / 63)$ were collected close to water bodies such as rivers or creeks, and 27\% (17/63) were collected near places with abundant endemic bamboo Chusquea spp., the tapirs' main source of food in this region [16]. According to forest cover, 37\% of the samples (23/ $63)$ were collected in paramo vegetation, $8 \%(5 / 63)$ in primary forest and 56\% (35/63) in secondary forest.

Based on previous field observations, tapirs frequently use latrines and these are usually located near spots with abundant Chusquea spp., important sites for tapirs as foraging and sleeping places [16]. Considering the population density of tapirs in the highlands (2.92 ind. $/ \mathrm{km}^{2}$ ) [2,5] and home range overlap in lowlands [17], the latrines and these places could be areas where different individuals share intestinal microbiota, therefore it is not possible to know whether more than one sample was collected from the same animal.

Dairy cattle and trout farms located near or in the study area may be a possible source of dissemination of resistance determinants to the environment; first, because of the potential runoff of resistant bacteria; and second, because several years ago some dairy cattle and trout farms were closed by health authorities owing to inadequate sewage water management in the region. In addition, tapirs are reported to inhabit close to human settlements $[2,3,16]$, however, it was not possible to sample near these farms. Hence, we suggest performing an analysis of antimicrobial resistance in faecal bacteria from livestock and trout as well as environmental bacteria (water or soil) around these farms to estimate the potential risk of the dissemination of resistance determinants to wild animals [18].

Based on the location of faeces, tapirs inhabit close to several human settlements in this area. The nearest human settlement was observed at $216 \mathrm{~m}$ from the nearest faeces collection site. Human settlements in this area consist of small villages and lodges. Most of them are located near RN2. Besides RN2, there are a few dirt roads in this area. Close contact of humans with tapirs is frequent due to habitat occupancy [3], moreover poaching still occurs. Consequently, human settlements, RN2 and dirt roads may be potential sources of dissemination of resistance determinants to the environment inhabited by tapirs.

Depending on the collection site, we proposed that landscape variables may have a different influence on the selective pressure for antimicrobial-resistant bacteria on the tapirs' intestinal microbiota. Therefore, it would be interesting to further determine individual exposure to the selective pressure for resistance determinant dissemination by each landscape variable, using a case-control study with molecular studies to identify individual animals.

A total of $60 \mathrm{E}$. coli isolates were obtained. Escherichia coli isolates were not recovered from three faecal samples collected at the highest altitude of all collection sites. The antimicrobial susceptibility profiles of these isolates presented 98\% (59/60) pansusceptibility. Only one sample showed resistance to nalidixic acid (Fig. 1). The low antimicrobial resistance obtained contrasts with several studies performed in wild animal samples in which high levels of resistance were detected $[6,11,12,19]$. The main difference of the current study is related to the landscape sampled. Most of the cited studies were performed in semi-urban places or areas where wild animals were in close/direct contact with humans and domestic animals. The current research was performed in a region where seven protected areas converge with a seemingly low anthropogenic activity. Anthropogenic activity or human proximity is the main force determining the genetic structure of commensal $E$. coli, therefore the antimicrobial resistance profile could be a reflection of anthropogenic activity $[6,9,10]$. The low antimicrobial resistance in isolates from wild animals may be related to the low exposure to antibiotics, or in places with a low anthropogenic activity where the natural evolution of the resistome tends to a low persistence of resistance mechanisms $[6,8,10,18,19]$. The current results suggest that the northwestern region of the Talamanca Mountain Range promotes a low selective pressure towards the acquisition of resistance genes in the intestinal microbiota of tapirs, probably due to low anthropogenic activity.

Antimicrobial susceptibility profiles among different wild animals sharing the same habitat may be similar [8]. Tapirs spend almost $90 \%$ of their activity foraging. These foraging sites are shared with other species [5,16]. As a sentinel species, the current findings might reflect the antimicrobial susceptibility situation of other species sharing this habitat with tapirs.

We propose that the environment inhabited by these tapirs promotes a very low dissemination of resistance determinants and therefore low acquisition of these determinants in the intestinal microbiota of tapirs. The results support the notion that habitats with an apparently low anthropogenic activity, such as protected areas where contact between humans, domestic animals and wildlife is scarce, decreases the probability of transmission of resistance determinants. Protected areas consequently have a positive impact in protecting animals from antibiotic selective pressure and anthropogenic activity. We consider this a valuable conservation input in terms of antimicrobial resistance, with the main aim to develop conservation strategies in regions near protected areas, such as antibiotic usage control by health authorities. 


\section{Acknowledgments}

The authors thank all of the park rangers from TMMNP and LQNP for their technical assistance during their visits, and the staff of Nai Conservation and the Bacteriology Laboratory of Universidad Nacional de Costa Rica (Heredia, Costa Rica).

\section{Funding}

This study was funded by the Bacteriology Laboratory of the School of Veterinary Medicine and by the Fondo para el Fortalecimiento de las Capacidades Estudiantiles [FOCAES-UNAVI-OFIC-212-2017] of the Universidad Nacional de Costa Rica.

\section{Competing interests}

None declared.

\section{Ethical approval}

This study was performed under the approval of the National Environment Ministry (MINAE) and the National System of Conservation Areas (SINAC), under the research permit SINACSE-CUS-PI-R-021-2016, with the corresponding scientific passport [SINAC-SE-022-2017].

\section{References}

[1] García M, Jordan C, O’Farril G, Poot C, Meyer N, Estrada N, et al. Tapirus bairdii. IUCN Red List of Threatened Species. International Union for Conservation of Nature (IUCN); 2016.

[2] Schank CJ, Cove MV, Kelly MJ, Mendoza E, O’Farrill G, Reyna-Hurtado R, et al. Using a novel model approach to assess the distribution and conservation status of the endangered Baird's tapir. Divers Distrib 2017;23:1459-71.

[3] Brenes-Mora E. Baird's tapir habitat use in a road-fragmented forest complex in the highlands of Costa Rica. In: Mills M, Rueda Fajardo X, Shanker K, editors. Proceedings of the 28th International Congress for Conservation Biology (ICCB 2017); 23-27 July 2017; Cartagena, Colombia. Washington, DC: Society for Conservation Biology; 2017. p. 289.

[4] O’Farrill G, Galetti M, Campos-Arceiz A. Frugivory and seed dispersal by tapirs: an insight on their ecological role. Integr Zool 2013;8:4-17.
[5] González-Maya JF, Shipper J, Polidoro B, Hoepker A, Zárrate-Charry D, Belant JL. Baird's tapir density in high elevation forests of the Talamanca region of Costa Rica. Integr Zool 2012;7:381-8.

[6] Carroll D, Wang J, Fanning S, McMahon BJ. Antimicrobial resistance in wildlife: implications for public health. Zoonoses Public Health 2015;62:534-42, doi: http://dx.doi.org/10.1111/zph.12182.

[7] Furness LE, Campbell A, Zhang L, Gaze WH, McDonald RA. Wild small mammals as sentinels for the environmental transmission of antimicrobial resistance. Environ Res 2017;154:28-34, doi:http://dx.doi.org/10.1016/j. envres.2016.12.014.

[8] Benavides JA, Godreuil S, Bodenham R, Ratiarison S, Devos C, Petretto MO, et al. No evidence for transmission of antibiotic-resistant Escherichia coli strains from humans to wild western lowland gorillas in Lopé National Park, Gabon. Appl Environ Microbiol 2012;78:4281-7, doi:http://dx.doi.org/10.1128/ AEM.07593-11.

[9] Österblad M, Norrdahl K, Korpimäki E, Huovinen P. Antibiotic resistance. How wild are wild mammals? Nature 2001;409:37-8, doi:http://dx.doi.org/ $10.1038 / 35051173$.

[10] Skurnik D, Ruimy R, Andremont A, Amorin C, Rouquet P, Picard B, et al. Effect of human vicinity on antimicrobial resistance and integrons in animal faecal Escherichia coli. J Antimicrob Chemother 2006;57:1215-9, doi:http://dx.doi. org/10.1093/jac/dkl122.

[11] Allen HK, Donato J, Wang HH, Cloud-Hansen KA, Davies J, Handelsman J. Call of the wild: antibiotic resistance genes in natural environments. Nat Rev Microbiol 2010;8:251-9, doi:http://dx.doi.org/10.1038/nrmicro2312.

[12] Cristóbal-Azkarate J, Dunn JC, Day JMW, Amábile-Cuevas CF. Resistance to antibiotics of clinical relevance in the fecal microbiota of Mexican wildlife. PLoS One 2014;9:e107719, doi:http://dx.doi.org/10.1371/journal. pone.0107719.

[13] Clinical and Laboratory Standards Institute. Performance standards for antimicrobial susceptibility testing. 27th ed. Wayne, PA: CLSI; 2017 CLSI supplement M100.

[14] QGIS Development Team. QGIS Geographic Information System. Open Source Geospatial Foundation Project. 2014 https://qgis.org. [Accessed 2 January 2019].

[15] Sistema Nacional de Información Territorial (SNIT). http://www.snitcr.go.cr. [Accessed 2 January 2019].

[16] Tobler MW. Habitat use and diet of Baird's tapirs (Tapirus bairdii) in montane cloud forest of the Cordillera de Talamanca, Costa Rica. Biotropica 2002;34: 468-74.

[17] Foerster CR, Vaughan C. Home range, habitat use, and activity of Baird's tapir in Costa Rica. Biotropica 2002;34:423-37, doi:http://dx.doi.org/10.1111/j.17447429.2002.tb00556.x.

[18] Hiltunen T, Virta M, Laine A-L. Antibiotic resistance in the wild: an ecoevolutionary perspective. Philos Trans R Soc B Biol Sci 2017;372:, doi:http://dx. doi.org/10.1098/rstb.2016.0039 pii: 20160039.

[19] Guenther S, Ewers C, Wieler LH. Extended-spectrum $\beta$-lactamases producing E. coli in wildlife, yet another form of environmental pollution? Front Microbiol 2011;2:246, doi:http://dx.doi.org/10.3389/fmicb.2011.00246. 